

\section{O PAPEL DO GUANXI}

\section{Ao estabelecer conexões com fornecedores na China, é importante entender as especificidades da cultura local e considerar que os gestores desse país valorizam o desenvolvimento de relações interpessoais como atalho para tomar decisões difíceis.}

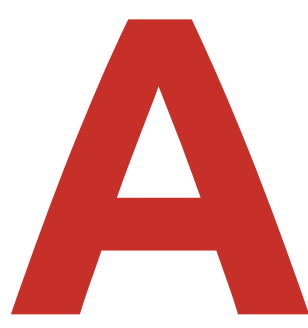

pós as cadeias de suprimentos tornarem-se globalizadas, a proximidade geográfica deixou de ser um fator preponderante na seleção de fornecedores, na maioria das situações. Mesmo que as empresas estejam revendo suas estratégias, devido a interrupções de fornecimento provocadas pela crise da Covid-19, esse movimento continuará progredindo. Assim, outros fatores passam a influenciar a seleção de novos parceiros internacionais. Um deles é a cultura de cada país.

Há recorrentes exemplos de fracassos de empresas que, ao desconsiderarem a cultura local, obtêm resultados aquém dos planejados. No Brasil, entre outras questões, a informalidade nas relações interpessoais é uma característica que também se transfere para o ambiente de negócios. Em outros países, como nos Estados Unidos, a familiaridade com eventos locais, como a final do Super Bowl, muitas vezes ajuda a quebrar o gelo. Na China, há a necessidade de se compreender o guanxi - um sistema de redes sociais e relações de influência que facilitam as relações interpessoais e os negócios.

\section{O fundamento do guanxi é o cultivo de relacionamentos de longo prazo, por meio de rituais de oferta de presentes, trocas de favores, atividades sociais, jantares e até banquetes.}

\section{ALGUMAS PALAVRAS SOBRE O GUANXI}

Estudos sobre cultura nacional, tal como o conduzido por Geert Hofstede, sugerem que há países notadamente mais coletivistas ou individualistas do que os outros. A China seria um exemplo com características mais coletivistas, inclusive por razões históricas. O coletivismo chinês é orientado às relações interpessoais, e uma de suas características é o guanxi (關係 ou 关系), no qual a construção de uma rede pessoal é quase imperativa. As relações construídas assumem papel utilitário e podem mobilizar recursos e influên- 


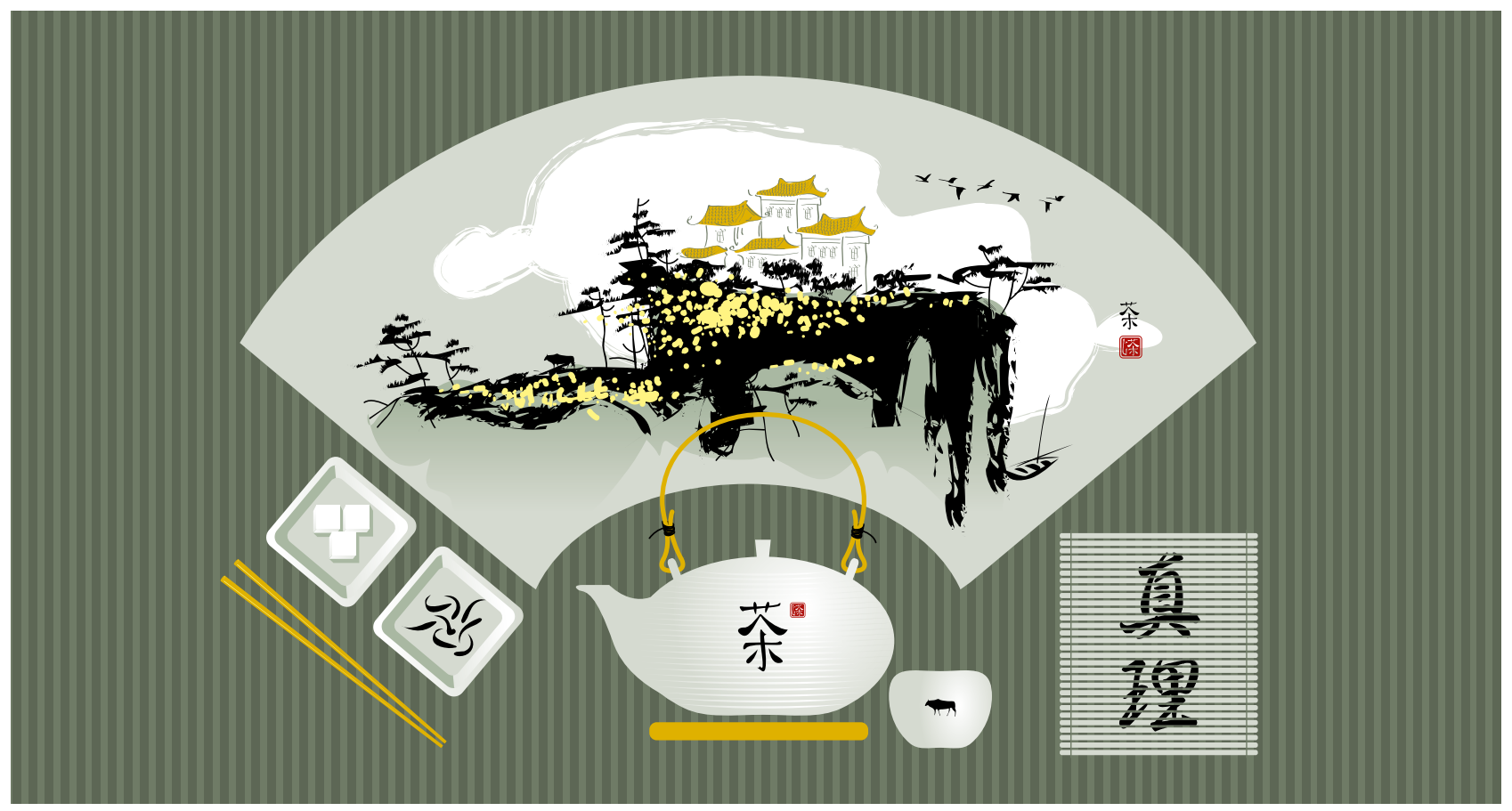

cias para ajudar os indivíduos a atingir seus objetivos. $\mathrm{O}$ fundamento dessa prática é o cultivo de relacionamentos de longo prazo, por meio de rituais de oferta de presentes, trocas de favores, atividades sociais, jantares e até banquetes. A dinâmica que busca construir é a de confiança, colaboração, e cria obrigações recíprocas, dependências mútuas, sentimento de dívida e expectativa de retorno.

Apesar da rede de relações do guanxi estar relacionada ao indivíduo, é também estendida às interações entre compradores e fornecedores. Por meio dessa prática, as empresas chinesas podem melhorar os vínculos de fornecimento.

É importante chamar a atenção para outro aspecto do guanxi: considerando-se que envolve trocas de presentes ou atividades como jantares, muitas vezes é visto, a partir da ótica da cultura ocidental, como uma prática controversa, sendo, até mesmo, entendido erroneamente como suborno. No entanto, para a boa inserção com fornecedores da China, devemos entendê-lo sob a ótica da cultura local. O principal objetivo do guanxi é fortalecer o relacionamento interpessoal. Vale ressaltar que nem sempre tais favores, ou utilidades potenciais do relacionamento, são exigidos pelas partes envolvidas. Desse modo, quando os indivíduos buscam pela construção do guanxi, concentrando-se apenas nos aspectos utilitários, não pela confiança estabelecida, as ações geralmente não são bem recebidas pela comunidade, gerando, até mesmo, desconfiança.

\section{O IMPACTO DO GUANXINA SELEÇÃO DE FORNECEDORES}

Para entender melhor qual o papel das relações pessoais na seleção de fornecedores no Brasil e na China, realizamos um experimento com aproximadamente 500 profissionais de ambos os países, no qual os participantes deveriam ter pelo menos três anos de experiência. No experimento, pedimos para os profissionais selecionarem um fornecedor entre as alternativas apresentadas, que combinavam relacionamento comprador-fornecedor e características do produto, como qualidade, custo e sustentabilidade.

O primeiro passo foi comparar as diferenças culturais potenciais presentes nas relações com fornecedores entre a China e o Brasil. Os dados confirmaram alguns dos aspectos já conhecidos do guanxi. Observamos que os respondentes chineses estavam mais propensos do que os brasileiros a considerar que um relacionamento pessoal mais próximo, desenvolvido com fornecedores, poderia levar a: obter uma melhor oportunidade de trabalho e promoção; e reduzir procedimentos e inspeções, para aumentar a agilidade dos processos organizacionais.

Quando analisamos a seleção do fornecedor, utilizando critérios de preço, qualidade, entrega confiável e sustentabilidade, os dados indicaram que, quando o comprador não tinha um relacionamento pessoal próximo com o fornecedor, não apareceram diferenças expressivas entre os crité- 


\section{Quando os indivíduos buscam pela construção do guanxi, concentrando-se apenas nos aspectos utilitários, não pela confiança estabelecida, as ações geralmente não são bem recebidas pela comunidade, gerando, até mesmo, desconfiança.}

rios de seleção de fornecedores atribuídos pelos profissionais dos dois países. Apenas a entrega confiável foi mais enfatizada pelos gestores chineses do que os demais critérios, enquanto o preço foi o mais destacado pelos brasileiros.

Entretanto, quando o comprador tinha uma relação pessoal mais próxima com o fornecedor, a decisão dos gestores chineses salientou primeiro o preço e depois o relacionamento pessoal, não dando maior destaque a outros critérios, como qualidade. Por outro lado, a decisão dos profissionais brasileiros também realçou, prioritariamente, o preço, mas o relacionamento interpessoal só foi considerado relevante após os critérios de sustentabilidade, entrega e qualidade.

O que esta pesquisa nos diz sobre a prática gerencial na seleção de fornecedores na China e no Brasil? De forma resumida, os resultados sugerem que em um contexto empresarial orientado para o coletivismo, como na China, quando os compradores não consideram o relacionamento pessoal para apoiar a decisão, o processo de compra é técnico e racional. Entretanto, quando os gestores são confrontados por uma seleção de fornecedores multicritério, tende-se a usar "atalhos mentais" na tomada de decisão racional. Como os respondentes chineses estão inseridos em uma cultura orientada para a relação interpessoal (o guanxi), utilizariam o relacionamento pessoal como atalho para ajudá-los a tomar mais rapidamente uma decisão complexa. Nesse processo, o relacionamento pessoal pode funcionar como um atributo até mais forte que os critérios de qualidade, entrega e sustentabilidade.

Vale ressaltar que não estamos defendendo que o relacionamento interpessoal seja bom ou ruim para a tomada de decisões, uma vez que os estudos foram inconclusivos a esse respeito.

\section{CONCLUSÃO}

Estabelecer relações de compra com empresas da China pode ser uma grande oportunidade para as brasileiras. A boa seleção de fornecedores influencia o desempenho em diversos fatores, tais como: custo, qualidade, inovação, flexibilidade, estratégia comercial e reputação.

Para ter êxito nesse movimento, as empresas brasileiras devem considerar a cultura local. Em países que valorizam o coletivismo mais marcadamente, como ocorre na China, o relacionamento interpessoal é presente, também, em processos organizacionais, como a seleção de fornecedores. Mesmo com a presença do guanxi, pode-se afirmar que a tomada de decisão é um processo racional em sua essência, que permite aos gestores decidir rapidamente quando as opções são complexas.

O guanxi, entretanto, pode trazer efeitos indesejáveis, se os resultados da seleção de fornecedores não forem constantemente otimizados. Um exemplo seria a manutenção com baixo desempenho no critério de qualidade, em razão do comprador da empresa possuir relações pessoais próximas com o fornecedor (ou um representante).

Por fim, entendermos como o guanxi funciona equivaleria a compreendermos muitos aspectos cotidianos da cultura brasileira, que também afetam o mundo dos negócios, como nosso apreço pela informalidade e algum nível de aversão às questões de mais longo prazo. Portanto, ao desenvolver relações com fornecedores na China, assim como com qualquer país, é de suma importância entender especificidades da cultura local, que podem influenciar diferentes processos, como a seleção de um fornecedor ou a efetivação de um contrato com um comprador de nossos produtos.

\footnotetext{
PARA SABER MAIS:

Geert Hofstede. Dimensionalizing cultures: The Hofstede model in context. Online readings in psychology and culture, v. 2, n.1, 2011. doi.org/10.9707/2307-0919.1014

Camila Lee Park e Ely Laureano Paiva. How do national cultures impact the operations strategy process? International Journal of Operations \& Production Management, v. 38, n. 10, 2018. doi.org/10.13140/RG.2.1.2950.2324

YEN-TSANG CHEN > Professor da NEOMA Business School - Reims Campus > yen-tsang.chen@neoma-bs.fr

ELY LAUREANO PAIVA > Professor da FGV EAESP > ely.paiva@fgv.br
} 